Papan Gypsum dari Serbuk Kayu dan Senyawa Bor

terhadap Sifat Mekanik dan Uji Bakar....Djoko Purwanto

\title{
PAPAN GYPSUM DARI SERBUK KAYU DAN SENYAWA BOR TERHADAP SIFAT MEKANIK DAN UJI BAKAR
}

\author{
Gypsum Board from Wood Sawdust and Boron Solution \\ on Mechanical Properties and Fire Resitant
}

\author{
Djoko Purwanto \\ Balai Riset dan Standardisasi Industri \\ JI. P. Batur Barat No.2. Telp./Fax. 0511-4772461/0511-4772115 Banjarbaru \\ E-mail : baristand.banjarbaru@gmail.com \\ Diterima 02 Agustus 2013, disetujui 04 Nopember 2013
}

\begin{abstract}
ABSTRAK
Pemanfaatan serbuk gergaji kayu Lua, Kambang, Tarap dan penambahan senyawa bor terhadap Kekuatan patah (MOR), kekuatan lentur (MOE) dan uji bakar (bagian yang terbakar) papan gypsum. Tujuan memanfaatkan serbuk kayu dan memperlambat proses pembakaran papan gypsum. Perlakuan penelitian yang digunakan yaitu kehalusan ukuran partikel serbuk kayu (40 mesh dan 60 mesh), persentase serbuk kayu dan gypsum (300\%, 400\% dan 500\%), dan persentase senyawa bor (1\% dan $2 \%$ ). Hasil penelitian menunjukkan bahwa nilai rata-rata kekuatan patah berada diantara $16,68-31,11 \mathrm{~kg} / \mathrm{cm}^{2}$; nilai rata-rata kekuatan lentur berada diantara 1129,80-3972,32 kg/cm ; dan nilai rata-rata uji bakar/bagian yang terbakar berada diantara 20,32-46,88\%. Nilai yang terbesar/terbaik untuk kekuatan patah $\left(31,11 \mathrm{~kg} / \mathrm{cm}^{2}\right)$, kekuatan lentur $(3972,32)$, dan bagian yang terbakar $(20,32 \%)$ dihasilkan pada perlakuan ukuran partikel serbuk kayu Kambang 40 mesh, persentase serbuk dan perekat gypsum 500\% dan senyawa bor $2 \%$. Makin beasr partikel ukuran partikel serbuk, jumlah perekat dan konsentrasi senyawa bor, maka nilai kekuatan patah dan lentur makin besar, dan persentase bagian yang terbakar makin kecil.
\end{abstract}

Kata kunci : papan gypsum, serbuk kayu, senyawa bor, kekuatan mekanik, uji bakar.

\section{ABSTRACT}

The using saw dust Lua, Kambang, Tarap wood and addition of boron solution on Modulus of Rupture (MOR), Modulus of Elasticity (MOE) and the fire resistant gypsum boar. The purpose of using saw dust wood and down the process of fire gypsum board. Treatment research that used of particle size (40 mesh and 60 mesh) saw dust wood, the percentage of sawdust and gypsum (300\%, 400\% and 500\%), and the percentage of boron solution (1\% and $2 \%$ ). The results showed that the average value of Modulus of Rupture is between 16.68 to $31.11 \mathrm{~kg} / \mathrm{cm} 2$; average Modulus of Elasticity is between 1129.80 to $3972.32 \mathrm{~kg} / \mathrm{cm} 2$, and the average value of the fire resistant is between 20.32 to $46.88 \%$. Value of the largest / best for Modulus of Rupture $(31.11 \mathrm{~kg} / \mathrm{cm} 2)$, Modulus of Elasticity $\left(3972.32 \mathrm{~kg} / \mathrm{cm}^{2}\right)$, and the burned area $(20.32 \%)$ resulted tha tratment of sawdust particle size Kambang 40 mesh, the percentage wood sawdust and gypsum $500 \%$ and $2 \%$ boron solution. The increasing particle size saw dust, and the amount of concentration gypsum, then the value Modulus of Rupture and ), Modulus of Elasticity the greater, and percentage the fire resistant small.

Keywords: gypsum board, wood sawdust, boron solution, mechanical strength, fire resistant. 


\section{PENDAHULUAN}

Papan/panel gypsum pada umumnya digunakan untuk bahan bangunan, dan sebagai aksesoris interior seperti pelapis atau dinding, dan plafon/langit-langit pada bangunan rumah/gedung. Permintaan produk papan gypsum dengan berbagai bentuk seperti persegi, oval, cekung, dan cembung dengan desain yang beragam semakin meningkat terutama untuk kebutuhan property

Limbah serbuk gergaji kayu yang dihasilkan dari industri penggergajian kayu sebesar $8,77 \%$ dari volume dolok yang berasal dari pembelahan awal dolok (break down), pembelahan kedua (resawing), pemerataan panjang/lebar papan/balok, dan pemotongan; sedangkan dari industri pengolahan kayu lapis dihasilkan limbah serbuk gergaji kayu sebesar 2,21\% volume yang terdiri dari potongan dolok, pengupasan venir, pemotongan venir dan pemotongan tepi kayu lapis; selama ini limbah serbuk gergaji kayu belum dimanfaatkan secara optimal yaitu untuk bahan bakar boiler pada industri (Purwanto, 2009).

Pada dasarnya proses pembuatan papan gypsum yaitu dari serbuk/bubuk gypsum yang dapat dicampur menggunakan serat/ fiber atau serat berlignoselulosa dan air (Rifcki, 2006). Sifat atau kelemahan papan gypsum antara lain bila bahan terbuat dari bahan berlignoselulosa seperti dari serbuk gergaji kayu dan terkena api akan mudah terbakar dan dapat mempercepat proses menjalarnya api ketempat bahan lain.

Senyawa bor (campuran natrium tetraborat/ $\mathrm{Na}_{2} \mathrm{~B}_{4} \mathrm{O}_{7}$ dengan asam borat $/ \mathrm{H}_{3} \mathrm{BO}_{3}$ ) dalam industri pengolahan kayu digunakan sebagai bahan untuk memperlambat proses pembakaran kayu atau memperbesar daya tahan rambat api terutama pada kayu-kayu struktural seperti balok, kaso dan tiang pada bangunan gedung atau rumah, dan hasilnya menunjukkan tendensi kayu untuk membara sangat kecil (Jusuf M, 1996).

Penelitian papan gypsum dari bahan limbah serbuk gergaji beberapa jenis kayu (kayu Lua, Kambang dan Tarap) dengan penambahan senyawa bor terhadap sifat mekanik dan uji bakar dengan tujuan untuk dapat memanfaatkan limbah serbuk gergaji kayu dan memperlambat proses pembakaran papan gypsum dari api. Diharapkan dari hasil penelitian ini dapat memperlambat proses kebakaran gedung atau rumah.

\section{BAHAN DAN METODE}

Bahan penelitian yang digunakan yaitu serbuk gergaji jenis kayu Lua (Ficus glomerata ROXB), kayu Kambang (Goniothalamus sp) dan kayu Tarap (Artocarpus sp) yang diperoleh dari industri penggergajian kayu di Banjarbaru Kalimantan Selatan, perekat tepung gypsum, air dan sebagai bahan untuk memperlambat perambatan api yaitu senyawa bor. Peralatan yang digunakan antara lain alat ayakan serbuk kayu dengan kehalusan 40 mesh, 60 mesh, cetakan, alat kempa, alat uji mekanik dan kelengkapan alat untuk uji bakar papan gypsum.

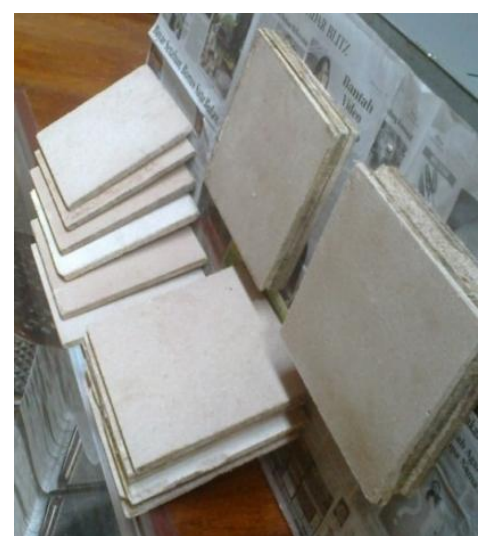

Gambar 1. Produk Papan Gypsum.

Serbuk gergaji kayu direndam dalam air selama 5 hari dengan tujuan untuk membersihkan kotoran-kotoran dan mengurangi zat yang menggangu dalam proses perekatan, kemudian dikeringkan secara alami hingga kadar air kering udara $12 \%$. Dilakukan pengayakan dengan kehalusan 40 mesh dan 60 mesh. Pembuatan papan gypsum dengan perbandingan serbuk kayu dan tepung 
gypsum $300 \%$, $400 \%$ dan $500 \%$, dan air secukupnya. Bahan senyawa bor $1 \%$ dan $2 \%$ dari berat tepung gypsum. Adonan yang dihasilkan dicetak dalam ukuran $25 \mathrm{~cm} \times 25 \mathrm{~cm} \times 1 \mathrm{~cm}$, dengan tekanan kempa dingin $10 \mathrm{~kg} / \mathrm{cm}^{2}$ selama 1 jam. Produk hasil dari cetakan dibiarkan untuk pengkondisian selama 30 hari (Gambar 1.)

Papan gypsum diuji kekuatan mekanik (keteguhan patah/ MOR dan keteguhan lentur/ MOE) dan dilakukan uji bakar (bagian yang terbakar). Perlakuan yang digunakan dalam penelitian yaitu persentase serbuk kayu ada 3 perlakuan (300\%, 400\%, dan 500\%), ukuran kehalusan serbuk gergaji kayu ada 2 perlakuan (40 mesh dan 60 mesh), persentase senyawa bor ada 2 perlakuan (1\% dan $2 \%$ ), dan jumlah perlakuan yaitu $3 \times 2 \times 2=12$, setiap perlakuan diulang sebanyak 2 kali. Jumlah contoh penelitian/uji yaitu $3 \times 2 \times 2 \times 2=24$ contoh. Pengujian mekanik papan gypsum mengacu pada Standar Nasional Indonesia (SNI) Papan Gypsum No. 03-6424-200, dan uji bakar (persentase bagian yang terbakar) mengacu pada ASTM E. 1191957 (for testing and material Part. 22. Wood adhesives). Penelitian ini menggunakan rancangan percobaan faktorial acak lengkap sederhana (Sudjana, 1997).

\section{HASIL DAN PEMB AHASAN}

\subsection{Kekuatan Patah}

Nilai rata-rata kekuatan patah papan gypsum dari limbah serbuk kayu Lua berada diantara $11,68-14,89 \mathrm{~kg} / \mathrm{cm}^{2}$ (Tabel 1). Nilai yang terkecil $(11,68 \mathrm{~kg} / \mathrm{cm})$ diperoleh pada perlakuan ukuran partikel 40 mesh, persentase gypsum dan serbuk $300 \%$, dan konsentrasi senyawa bor $1 \%$; dan nilai yang terbesar $\left(14,89 \mathrm{~kg} / \mathrm{cm}^{2}\right)$ dihasilkan dari perlakuan ukuran partikel 40 mesh, persentase serbuk dan gypsum $500 \%$ dan persentase senyawa bor $2 \%$ (Tabel 1).

Nilai rata-rata kekuatan patah papan gypsum dari limbah serbuk kayu Kambang berada diantara $25,10-31,11 \mathrm{~kg} / \mathrm{cm}^{2}$ (Tabel 2). Nilai yang terkecil $\left(25,10 \mathrm{~kg} / \mathrm{cm}^{2}\right)$ dihasilkan dari perlakuan ukuran partikel 60 mesh, perbandingan serbuk dan gypsum $300 \%$, dan senyawa bor $1 \%$. Nilai yang terbesar $\left(31,11 \mathrm{~kg} / \mathrm{cm}^{2}\right)$ diperoleh dari perlakuan ukuran partikel 40 mesh, perbandingan serbuk dan gypsum 500\%, dan senyawa bor $2 \%$ (Tabel 2).

Nilai rata-rata kekuatan patah papan gypsum dari limbah serbuk kayu Tarap berada diantara $19,20-24,18 \mathrm{~kg} / \mathrm{cm}^{2}$ (Tabel 3). Nilai yang terkecil $\left(19,20 \mathrm{~kg} / \mathrm{cm}^{2}\right)$ diperoleh pada perlakuan ukuran partikel 60 mesh, persentase serbuk dan gypsum $300 \%$, dan senyawa bor $1 \%$. Nilai yang terbesar $\left(24,18 \mathrm{~kg} / \mathrm{cm}^{2}\right)$ dihasilkan dari perlakuan ukuran partikel 40 mesh, perbandingan serbuk dan gypsum 500\%, dan senyawa bor $2 \%$ (Tabel 3).

Secara umum baik dari bahan limbah serbuk kayu Lua, Kambang dan Tarap dapat dikemukan bahwa penggunaan ukuran partikel 40 mesh; dan perbandingan serbuk dan perekar 500\% menghasilkan kekuatan patah yang lebih beasr dibandingakan ukuran partikel 60 mesh perekat gypsum $300 \%$ dan $400 \%$, hal ini dikarenakan ukuran partikel 40 mesh lebih besar dan didukung oleh penambahan jumlah perekat gypsum sehingga menyebabkan daya ikatan antara partikel kayu dengan perekat lebih kuat. Sifat fisik mekanik bahan baku papan gypsum dari jenis kayu Lua, Kambang dan Tarap juga mempengaruhi terhadap nilai kekuatan patah lentur papan gypsum yang dihasilkan. Kayu Lua memiliki berat jenis 0,32 ; kuat lentur $264,70 \mathrm{~kg} / \mathrm{cm}^{2}$; dan kuat tekan 212,95 $\mathrm{kg} / \mathrm{cm}^{2}$. Kayu Kambang memiliki berat jenis 0,48 , kuat lentur 312,65 $\mathrm{kg} / \mathrm{cm}^{2}$ dan kuat tekan $266,21 \mathrm{~kg} / \mathrm{cm}^{2}$; Kayu Tarap memilki berat jenis 0,25; kuat lentur $126,17 \mathrm{~kg} / \mathrm{cm}^{2}$ dan kuat tekan 220,74 $\mathrm{kg} / \mathrm{cm}^{2}$ (Purwanto, 2010). Makin besar berat jenis serta kuat lentur dan tekan kayu maka makin besar kekuatan patah papan gypsum. Namun nilai kekuatan patah papan gypsum dari limbah serbuk kayu Lua, Kambang dan Tarap belum memenuhi persyaratan kekuatan patah papan gypsum yang dipersyaratkan dalam SNI 03-64342000 yaitu $100-140 \mathrm{~kg} / \mathrm{cm}^{2}$. Penggunaan bahan serbuk kayu belum bisa sebagai bahan substitusi pembuatan papan gypsum. Hal ini kemungkinan serbuk kayu 
belum bisa sebagai agen penguat dalam panel gypsum, sedangkan menurut Rifcki (2006) bahwa papan gypsum dalam pembuatannya diperlukan bahan dalam bentuk serat/fiber. Dari analisis sidik ragam (Tabel 4) menunjukkan bahwa perlakuan persentase perekat gypsum dan penambahan konsentrasi senyawa bor menunjukkan pengaruh sangat nyata terhadap kekuatan patah, dalam hal ini menghasilkan kekuatan patah yang lebih besar.

\subsection{Kekuatan Lentur}

Nilai rata-rata kekuatan lentur papan gypsum dari serbuk kayu Lua berada diantara 1129,80 - 2092,70 kg/cm ${ }^{2}$ (Tabel 1). Nilai yang terendah $\left(1129,80 \mathrm{~kg} / \mathrm{cm}^{2}\right)$ dihasilkan pada perlakuan ukuran partikel 60 mesh, persentase gypsum dan serbuk $300 \%$ dan senyawa bor $1 \%$. Nilai yang terbesar $\left(2092,70 \mathrm{~kg} / \mathrm{cm}^{2}\right)$ diperoleh dari perlakuan ukuran partikel 40 mesh, persentase gypsum dan serbuk $500 \%$ dan senyawa bor $2 \%$ (Tabel 1 ).

Nilai rata-rata kekuatan lentur papan gypsum dari serbuk kayu Kambang berada diantara 2512,37-3971,32 kg/ $\mathrm{cm}^{2}$ (Tabel 2). Nilai yang terendah $\left(2512,37 \mathrm{~kg} / \mathrm{cm}^{2}\right)$ diperoleh dari perlakuan ukuran partikel 60 mesh, perbandingan serat dan gypsum $300 \%$ dan senyawa bor $1 \%$. Nilai yang terbesar $\left(3971,32 \mathrm{~kg} / \mathrm{cm}^{2}\right.$ ) dihasilkan pada perlakuan ukuran partikel 40 mesh, perbandingan serat dan gypsum 500\%, dan senyawa bor $2 \%$ (Tabel 2 ).

Nilai rata-rata kekuatan lentur papan gypsum dari serbuk kayu Tarap berada diantara 2140,21-2691,09 kg/cm² (Tabel 3). Nilai yang terendah $\left(2140,21 \mathrm{~kg} / \mathrm{cm}^{2}\right)$ diproleh pada perlakuan ukuran partikel 40 mesh, perbandingan serat dan gypsum $300 \%$, dan senyawa bor $1 \%$. Nilai yang terbesar dihasilkan dari perlakuan ukuran partikel 40 mesh, perbandingan serbuk dan gypsum $500 \%$, dan senyawa bor $2 \%$ (Tabel 3).

Pengunanan bahan baku serbuk gergaji kayu dari jenis kayu kambang lebih besar kekuatan lenturnya dibandingkan dari kayu Lua dan Tarap. Ukuran partikel 40 mesh dan perekat gypsum 500\% menyebabkan kekuatan lentur lebih besar dibandingkan ukuran partikel 60 mesh dan perekat $300 \%$ dan $400 \%$. Nilai Kekuatan lentur diantaranya dipengaruhi oleh elastisitas bahan baku yang digunakan. Standar Nasional Indonesia 03-6434-2000 tidak mempersyaratkan kekuatan lentur dalam papan gypsum. Hasil analisis sidik ragam pada Tabel 4. menunjukkan penambahan perekat gypsum dan konsentrasi senyawa bor menghasilkan pengaruh sangat nyata, dalam arti dapat menambah kekuatan lentur.

\subsection{Uji Bakar/Bagian yang Terbakar}

Nilai rata-rata uji bakar papan gypsum dari serbuk kayu Lua berada diantara 30,11-40,15\% (Tabel 1). Nilai yang terendah bagian yang terbakar $(30,11 \%)$ dihasilkan dari perlakuan ukuran partikel 40 mesh, persentase gypsum dan serbuk $500 \%$, dan senyawa bor $2 \%$. Nilai yang terbesar $(40,15 \%)$ diperoleh pada perlakuan ukuran partikel 60 mesh, persentase gypsum dan serbuk $300 \%$ dan senyawa bor $1 \%$ (Tabel 1$)$.

Nilai rata-rata uji bakar papan gypsum dari serbuk kayu Kambang berada diantara 20,32 - 26,70\% (Tabel 2). Nilai yang terendah $(20,32 \%)$ bagian yang terbakar diperoleh pada perlakuan ukuran partikel 40 mesh, perbandingan serat dan gypsum $500 \%$, senyawa bor $2 \%$. Nilai yang terbesar $(26,70 \%)$ dihasilkan dari perlakuan ukuran partikel serbuk 60 mesh, perbandingan serbuk dan gypsum $400 \%$, dan senyawa bor $1 \%$ (Tabel 2).

Nilai rata-rata uji bakar papan gypsum dari serbuk kayu Tarap berada diantara 32,16-46,88\% (Tabel 3). Nilai yang terendah $(32,16 \%)$ bagian yang terbakar dihasilkan dari perlakuan ukuran partikel 40 mesh, perbandingan serbuk dan gypsum $500 \%$, dan senyawa bor $2 \%$. Nilai yang terbesar $(46,88 \%)$ diperoleh dari perlakuan ukuran partikel 60 mesh, dan perbandingan serbuk dan gypsum 300\%, dan senyawa bor $1 \%$ (Tabel 3).

Makin kecil persentase bagian yang terbakar maka papan gypsum makin lambat proses pembakarannya. Dalam arti papan gypsum memliki daya tahan api yang lebih baik. Penambahan senyawa bor $2 \%$ menghasilkan daya rambat api yang 
Papan Gypsum dari Serbuk Kayu dan Senyawa Bor terhadap Sifat Mekanik dan Uji Bakar....Djoko Purwanto

lebih lambat dibandingkan senyawa bor $1 \%$. Kayu yang memiliki berat jenis dan kerapatan, serta kekuatan mekanik yang besar akan terjadi proses pembakaran yang lebih lambat dibandingkan kayu yang memiliki berat jenis dan kekuatan mekanik yang rendah. Menurut Purwanto dan Arhamsyah (2009), kecepatan pembakaran suatu produk kayu tergantung pada kecepatan akumulasi panas pada permukaan kayu, dan ini dipengaruhi antara lain oleh faktor dimensi kayu dan kecepatan pembakaran dan kobaran api pada kayu. Disisi lain dalam SNI 03-35281994 penggunaan senyawa bor dapat sebagai bahan pengawet kayu untuk mencegah jasad perusak kayu (rayap, bubuk, dan jamur kayu) dalam bangunan gedung dan rumah. Dari Tabel 4. Analisis sidik ragam menunjukkan bahwa penambahan konsentrasi serbuk gypsum dan senyawa bor menghasilkan pengaruh sangat nyata, dalam arti menghasilkan uji bakar papan gypsum yang lebih lama.

\section{KESIMPULAN}

Hasil nilai kekuatan patah papan gypsum dari limbah serbuk kayu jenis kayu Lua, Kambang dan Tarap belum memenuhi syarat Standar Nasional Indonesia 03-6434-2000. Penambahan persentase serbuk gypsum dalam pembuatan papan gypsum dapat menambah kekuatan patah dan lentur papan gypsum.

Penambahan senyawa bor pada pembuatan papan gypsum dapat memperlambat atau mengurangi bagian yang terbakar pada papan gypsum saat proses pembakaran. Perlakuan konsentrasi perekat gypsum dan senyawa bor menunjukkan pengaruh sangat nyata terhadap kekuatan patah, lentur dan uji bakar papan gypsum.

\section{DAFTAR PUSTAKA}

1. Anonim. 1975. Annual Book of American Society for testing and Material (ASTM). E. 119-1975 Standars. Part. 22. Wood Adhesives.
2. Anonim. 1994. Pengawetan Kayu untuk Rumah dan Gedung. SNI. 03-35281994. Jakarta : Dewan Standardisasi Nasional.

3. Anonim. 2000. Papan Gypsum. Standar Nasional Indonesia (SNI). 03-64242000. Jakarta : Badan Standar Nasional Indonesia.

4. Anonim, 2012. Laporan Penelitian Pemanfaatan Limbah Industri Gergajian untuk Pembuatan Produk Interior. Balai Riset dan Standardisasi Industri Banjarbaru.

5. Hurt, GM dan Garrat GA di dalam Jusuf. M.1996. Pengawetan Kayu. Edisi Pertama. Jakarta : Akademika Pressindo.

6. Purwanto. D. 2009. Analisa Jenis Limbah Kayu Pada Industri Pengolahan Kayu Di Kalimantan Selatan. Jurnal Riset Industri Hasil Hutan. 1 (1). 14 - 20. 2009. Balai Riset dan Standardisasi Industri. Banjarbaru.

7. Purwanto. D, dan Arhamsyah. 2009. Peningkatan Daya Tahan Rambat Api Kayu Lapis Dengan Cara Pelaburan Natrium Silikat Pada Venir. Jurnal Riset Industri Hasil Hutan. 1 (2). 25-29. 2009. Balai Riset dan Standardisasi Industri Banjarbaru.

8. Purwanto. D. 2010. Peningkatan Kenampakan Serat dan Warna Beberapa Jenis Kayu Kurang Dikenal untuk Bahan Mebel. Jurnal Riset Industri Hasil Hutan. 2(1).1-8.2010. Balai Riset dan Standardisasi Industri. Banjarbaru.

9. Rifcki. 2006. Sifat Fisik Dan Mekanis papan Gypsum Dari Kayu Gmelina arborea ROXB Pada Berbagai Kadar Gypsum dan perlakuan Pendahuluan. Departemen Hasil Hutan. Bogor : Fakultas Kehutanan IPB.

10. Sudjana.1997. Desain dan Analisis Eksperimen. Jakarta : PT. Tarsito. 
Tabel 1. Nilai Rata - rata Kekuatan patah, lentur dan uji bakar Papan Gypsum dari serbuk kayu lua

\begin{tabular}{ccccccc}
\hline & & & & & Hasil uji \\
\cline { 5 - 7 } No. & $\begin{array}{c}\text { Ukuran partikel } \\
(\text { mesh) }\end{array}$ & $\begin{array}{c}\text { Persentase } \\
\text { serbuk kayu } \\
\text { dan gypsum }\end{array}$ & $\begin{array}{c}\text { Senyawa } \\
\text { Bor } \\
(\%)\end{array}$ & $\begin{array}{c}\text { Kekuatan } \\
\text { Patah/MOR } \\
\left(\mathrm{kg} / \mathrm{cm}^{2}\right)\end{array}$ & $\begin{array}{c}\text { Kekuatan } \\
\text { lentur/MOE } \\
\left(\mathrm{kg} / \mathrm{cm}^{2}\right)\end{array}$ & $\begin{array}{c}\text { Uji bakar } \\
(\%)\end{array}$ \\
\hline 1. & 40 & 300 & 1 & 12,69 & 1550,73 & 37,10 \\
\hline 2. & 40 & 300 & 2 & 12,75 & 1538,53 & 31,60 \\
\hline 3. & 40 & 400 & 1 & 12,55 & 1767,92 & 34,18 \\
\hline 4. & 40 & 400 & 2 & 11,68 & 1962,90 & 30,90 \\
\hline 5. & 40 & 500 & 1 & 14,47 & 1853,26 & 30,66 \\
\hline 6. & 40 & 500 & 2 & 14,89 & 2092,70 & 30,11 \\
\hline 7. & 60 & 300 & 1 & 12,10 & 1129,80 & 40,15 \\
\hline 8. & 60 & 300 & 2 & 12,15 & 1235,15 & 35,13 \\
\hline 9. & 60 & 400 & 1 & 11,90 & 1322,75 & 37,65 \\
\hline 10. & 60 & 400 & 2 & 11,77 & 1364,66 & 34,09 \\
\hline 11. & 60 & 500 & 1 & 12,17 & 1412,15 & 35,19 \\
\hline 12. & 60 & 500 & 2 & 12,68 & 1492,50 & 33,98 \\
\hline
\end{tabular}

Tabel 2. Nilai Rata-rata Kekuatan patah, lentur dan uji bakar Papan Gypsum dari serbuk kayu Kambang

\begin{tabular}{ccccccc}
\hline No. & Ukuran & Persentase & Senyawa & & \multicolumn{3}{c}{ Hasil uji } \\
\cline { 5 - 7 } & $(\mathrm{mesh})$ & $\begin{array}{c}\text { Serbuk kayu } \\
\text { dan gypsum }\end{array}$ & $\begin{array}{c}\text { Bor } \\
(\%)\end{array}$ & $\begin{array}{c}\text { Kekuatan } \\
\text { Patah/MOR } \\
\left(\mathrm{kg} / \mathrm{cm}^{2}\right)\end{array}$ & $\begin{array}{c}\text { Kekuatan } \\
\text { lentur/MOE } \\
\left(\mathrm{kg} / \mathrm{cm}^{2}\right)\end{array}$ & $\begin{array}{c}\text { Uji bakar } \\
(\%)\end{array}$ \\
\hline 1. & 40 & 300 & 1 & 28,72 & 2981,64 & 25,16 \\
\hline 2. & 40 & 300 & 2 & 29,03 & 3017,12 & 21,16 \\
\hline 3. & 40 & 400 & 1 & 25,50 & 3216,42 & 23,54 \\
\hline 4. & 40 & 400 & 2 & 26,98 & 3490,29 & 20,74 \\
\hline 5. & 40 & 500 & 1 & 29,63 & 3780,78 & 23,02 \\
\hline 6. & 40 & 500 & 2 & 31,11 & 3971,32 & 20,32 \\
\hline 7. & 60 & 300 & 1 & 25,10 & 2512,37 & 29,41 \\
\hline 8. & 60 & 300 & 2 & 26,14 & 2756,01 & 22,60 \\
\hline 9. & 60 & 400 & 1 & 25,48 & 2952,19 & 26,70 \\
\hline 10. & 60 & 400 & 2 & 28,70 & 3064,14 & 21,83 \\
\hline 11. & 60 & 500 & 1 & 27,97 & 3070,15 & 25,91 \\
\hline 12. & 60 & 500 & 2 & 29,61 & 3353,96 & 21,55 \\
\hline
\end{tabular}


Papan Gypsum dari Serbuk Kayu dan Senyawa Bor terhadap Sifat Mekanik dan Uji Bakar....Djoko Purwanto

Tabel 3. Nilai Rata-rata Kekuatan patah, lentur dan uji bakar Papan Gypsum dari serbuk kayu Tarap

\begin{tabular}{|c|c|c|c|c|c|c|}
\hline \multirow[b]{2}{*}{ No. } & \multirow[b]{2}{*}{$\begin{array}{l}\text { Ukuran } \\
\text { partikel } \\
\text { (mesh) }\end{array}$} & \multirow[b]{2}{*}{$\begin{array}{l}\text { Persentase } \\
\text { serbuk kayu } \\
\text { dan gypsum }\end{array}$} & \multirow[b]{2}{*}{$\begin{array}{c}\text { Senyawa } \\
\text { Bor } \\
(\%)\end{array}$} & \multicolumn{3}{|c|}{ Hasil uji } \\
\hline & & & & $\begin{array}{c}\text { Kekuatan } \\
\text { Patah/MOR } \\
\left(\mathrm{kg} / \mathrm{cm}^{2}\right)\end{array}$ & $\begin{array}{c}\text { Kekuatan } \\
\text { lentur/MOE } \\
\left(\mathrm{kg} / \mathrm{cm}^{2}\right)\end{array}$ & $\begin{array}{l}\text { Uji bakar } \\
(\%)\end{array}$ \\
\hline 1. & 40 & 300 & 1 & 20,46 & 2050,63 & 40,08 \\
\hline 2. & 40 & 300 & 2 & 21,14 & 2140,21 & 37,85 \\
\hline 3. & 40 & 400 & 1 & 22,71 & 2414,70 & 40,71 \\
\hline 4. & 40 & 400 & 2 & 24,18 & 2571,64 & 35,72 \\
\hline 5. & 40 & 500 & 1 & 21,55 & 2497,23 & 38,46 \\
\hline 6. & 40 & 500 & 2 & 22,10 & 2691,09 & 32,16 \\
\hline 7. & 60 & 300 & 1 & 19,20 & 2081,17 & 46,88 \\
\hline 8. & 60 & 300 & 2 & 19,24 & 2243,68 & 42,59 \\
\hline 9. & 60 & 400 & 1 & 19,64 & 2175,63 & 45,52 \\
\hline 10. & 60 & 400 & 2 & 20,52 & 2308,50 & 40,63 \\
\hline 11. & 60 & 500 & 1 & 20,32 & 2251,10 & 45,17 \\
\hline 12. & 60 & 500 & 2 & 20,70 & 2515,91 & 40,28 \\
\hline
\end{tabular}

Tabel 4. Ringkasan Analisis Sidik Ragam Kekuatan Patah, Kekuatan Lentur dan Uji Bakar Papan Gypsum

\begin{tabular}{|c|c|c|c|c|c|c|c|}
\hline \multirow[b]{2}{*}{ No } & \multirow[b]{2}{*}{$\begin{array}{l}\text { Jenis serbuk kayu/ } \\
\text { Sumber keragaman }\end{array}$} & \multirow[b]{2}{*}{$\mathrm{db}$} & \multicolumn{3}{|c|}{ F hitung Parameter uji } & \multirow[b]{2}{*}{$\begin{array}{c}\mathrm{F} \text { tabel } \\
5 \%\end{array}$} & \multirow[b]{2}{*}{$\begin{array}{c}\mathrm{F} \text { tabel } \\
1 \%\end{array}$} \\
\hline & & & $\begin{array}{l}\text { Kekuatan } \\
\text { patah/MOR }\end{array}$ & $\begin{array}{l}\text { Kekuatan } \\
\text { lentur/MOE }\end{array}$ & Uji bakar & & \\
\hline 1. & $\begin{array}{l}\text { Kayu Lua } \\
\text { Perlakuan } \\
\text { Kesalahan }\end{array}$ & $\begin{array}{l}11 \\
24\end{array}$ & $524,00 * *$ & $1391,25^{\star *}$ & $587,79^{* *}$ & 2,22 & 3,09 \\
\hline 2. & $\begin{array}{l}\text { Kayu Kambang } \\
\text { Perlakuan } \\
\text { Kesalahan }\end{array}$ & $\begin{array}{l}11 \\
24\end{array}$ & $1761,12^{* *}$ & $1547,86^{* *}$ & $965,48^{* *}$ & 2,22 & 3,09 \\
\hline 3. & $\begin{array}{l}\text { Kayu Tarap } \\
\text { Perlakuan } \\
\text { Kesalahan }\end{array}$ & $\begin{array}{l}11 \\
24\end{array}$ & $139,29^{\star *}$ & $475,09^{* *}$ & $1211,03^{* *}$ & 2,22 & 3,09 \\
\hline
\end{tabular}

$\left.{ }^{* *}\right)$ Berpengaruh sangat nyata 
